\title{
Calcitonin in fine-needle aspirate washout fluid and serum for the differential diagnosis of Medullary Thyroid Carcinomain patients with thyroid nodules
}

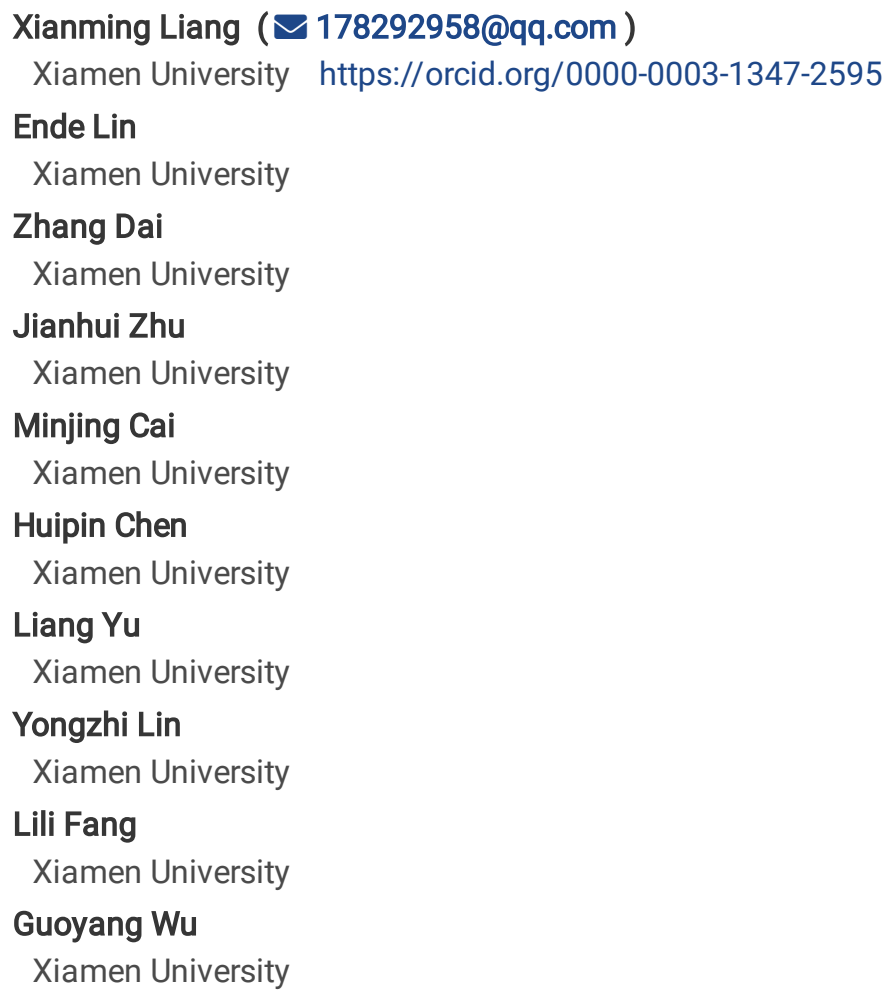




\section{Abstract}

Purpose

To assess a cutoff value and the diagnosis performance of CT in fine-needle aspirate washout fluid (FNA-CT) and serum in consecutive patients with thyroid nodules by chemiluminescence immunoassay method (CLIA).

Methods

1,941 healthy persons, 212 patients with 235 thyroid nodules were investigated. They were classified into were classified into healthy, nodular goiter, chronic thyroiditis, thyroid follicular neoplasm, papillary thyroid carcinoma, follicular thyroid carcinoma and medullary thyroid carcinoma. Serum CT and FNA-CT were measured by CLIA.

Results

Serum CT median concentration in MTC was $301.0 \mathrm{pg} / \mathrm{mL}$, significantly higher than other groups. The cutoff value of serum CT was $13.8 \mathrm{pg} / \mathrm{mL}$, leading $100.00 \%$ sensitivity, $97.99 \%$ specificity and 0.86 Kappa value in MTC. The FNA-CT median concentration in MTC nodules was $5000.0 \mathrm{pg} / \mathrm{mL}$, significantly higher than other groups. A receiver operating characteristic analysis of MTC nodules and non-MTC nodules indicated that the cutoff value was $91.6 \mathrm{pg} / \mathrm{mL}$, leading to $100.00 \%$ sensitivity, $97.25 \%$ specificity and $0.84 \mathrm{Kappa}$ value.

Conclusion

FNA-CT and serum were perfect marker for the differential diagnosis of medullary thyroid carcinoma in patients with thyroid nodules. The optimal cutoff values with CLIA were $13.8 \mathrm{pg} / \mathrm{mL}$ and $91.6 \mathrm{pg} / \mathrm{mL}$, respectively.

\section{Introdution}

Medullary Thyroid Carcinoma (MTC) is a neuroendocrine tumor caused by a malignant transformation in the parafollicular C-cells of the thyroid and constitutes between 1 and $2 \%$ of all thyroid carcinomas [1]. The targeted systemic therapies based on tyrosine kinase inhibitors (i.e. vandetanib and cabozantinib) have been approved for advanced and progressive MTC [1, 2]. Early diagnosis and treatment of MTC is critical for optimal patient outcomes. The main tumor markers (TM) used in MTC are serum calcitonin(CT) and carcinoembryonic antigen (CEA) $[1,3]$. The best test for MTC is the presence of an elevated CT, since only rarely is the level normal. There are three methods of usefulness of CT in MTC: serum CT, stimulated CT and the CT in fine-needle aspirate washout fluid (FNA$\mathrm{CT})[4,5]$. Measurement of CT has been recommended for patients with a suspicious history, or cytology for MTC, or referred for thyroidectomy [2]. It is important to periodically determine CT and stimulated CT, because of the familial incidence of MTC $[4,6]$. FNACT is an ancillary method to increase the accuracy of diagnosis in MTC [7]. According to the report by Rosario, CT could be superior to stimulated CT [8]. However, the diagnosis of MTC cannot always be excluded by a normal preoperative CT level $[9,10]$. Moreover, there are analytical, physiological, pharmacological, and pathological factors that can influence results of serum CT values. Due to the influence of these factors, there is a high variability in assay-dependent cutoffs $[4,11,12]$. There is controversy regarding cutoff value of CT for earlier and more accurate differential diagnosis of MTC in different populations. No data are available about cutoff values of serum CT and FNA-CT using the currently available by chemiluminescence immunoassay method (CLIA) by now. Furthermore, it is important to evaluate the sensitivity and specificity for each methods of usefulness of CT or in combination in diagnosing MTC. The aims of this study were to investigate the concentrations of CT and FNA- CT as predictors of MTC in consecutive patients with thyroid nodules by CLIA, to assess cutoff value of FNA-CT for clinical practice, and to analysis the diagnosis performance.

\section{Materials And Methods}

\section{Study population}

Consecutive patients with thyroid nodules who underwent FNAC under ultrasonographic guidance between May 2017 and May 2019 in Zhongshan Hospital, were prospectively evaluated. Zhongshan Hospital is a large integrated Grade III A hospital that provides approximately 3.50 million people with health care and outpatient medical and hospital services per year. In total, 1,941 healthy persons and 212 patients with 235 thyroid nodules were investigated. All of the patients with nodules were diagnosed with histological techniques or cytologic evaluation. The final diagnosis of the nodules was based on surgical specimen. According to histopathological 
diagnoses, the nodules were classified into nodular goiter, chronic thyroiditis, follicular neoplasm, papillary carcinoma, follicular carcinoma or medullary carcinoma. The clinical biochemical and imaging index were normal in the healthy subjects, including screening ultrasound to confirm no nodules.

\section{Assays}

Fine-needle aspirate cytology (FNAC) was performed by using a 25-gauge needle under ultrasound guidance. Following the smear preparation, the remaining aspirate in the syringe and needle was rinsed with $1.0 \mathrm{~mL}$ of saline. The fine-needle aspirate washout fluid was centrifuged at $3000 \mathrm{rpm}$ for $10 \mathrm{~min}$, and clear supernatants were removed and stored at $-80^{\circ} \mathrm{C}$. The clear supernatants was then subjected to CT measurements. Blood samples were obtained by venous puncture at the same time. The blood samples were centrifuged at $3000 \mathrm{rpm}$ for $10 \mathrm{~min}$ and the upper serum was used. FNA-CT and serum CT were measured with a CLIA, applied on the Maglumi 2000 Plus automated platform (Shenzen New Industries Biomedical Engineering (SNIBE, Shenzen, China). The Maglumi 2000 Plus is a continuous random access CLIA system that uses $\mathrm{N}$-(aminobutil)-N-(ethyl)-isoluminol (ABEI) as luminescence substrate and magnetic particles that serve both the solid phase and the separator in a liquid phase, with two different monoclonal antibodies labeled with either $\mathrm{ABEl}$ or fluoresceine-5-isothiocyanate. The detection limit of the instrument ranges from 2.0 to $5000.0 \mathrm{pg} / \mathrm{mL}$. The readings higher than $5000.0 \mathrm{pg} / \mathrm{ml}(>5000.0 \mathrm{pg} / \mathrm{mL})$ were recorded as $5000.0 \mathrm{pg} / \mathrm{mL}$, whereas those that were lower than $2.0 \mathrm{pg} / \mathrm{ml}(<2 \mathrm{pg} / \mathrm{mL})$ were recorded as $2.0 \mathrm{pg} / \mathrm{mL}$.

\section{Statistical analysis}

Statistical analysis was carried out using IBM SPSS statistics version 20 (SPSS, Inc, Chicage, IL, USA) and Graph-Pad Prism version 8.00 (GraphPadSofeware, San Diegl, CA, USA). Statistical significance was set at a p-value of lower than $0.05(<0.05)$. The continuous variables that did not follow a normal distribution were reported as medians with interquartile range (IQR). The statistical analysis for the comparison among groups was conducted using the Kruskal-Wallis and the Mann-Whitney U-tests. The relationship between the abnormal CT and the clinical diagnosis was calculated by the kappa test. The agreement of the results according to their kappa values was categorized as near perfect ( 0.81 to 1.00 ), substantial ( 0.61 to 0.80$)$, moderate ( 0.41 to 0.60$)$, fair ( 0.21 to 0.40$)$, slight ( 0.00 to $0.20)$, or poor $(<0.00)[13]$. A p value of less than $0.05(<0.05)$ was considered statistically significant.

\section{Results}

\section{Characteristics of patients and thyroid nodules}

A total of 235 thyroid nodules in 212 patients participated in the study. The histopathological diagnoses of these nodules included nodular goiter (62 nodules), chronic thyroiditis (three nodules), follicular neoplasm (14 nodules), papillary carcinoma (135 nodules), follicular carcinoma (four nodules) and medullary carcinoma (17 nodules) (Table 1). The median age of the patients was 42 years (range, 16-82). A total of 50 males (23.6\%) and 162 females (76.4\%) were included. The age range of the healthy subjects was 22 to 84 years. A total of 1,126 males (58.0\%) and 815 females (42.0\%) were included in the healthy group. Clinical stage included stage $\square(117)$,

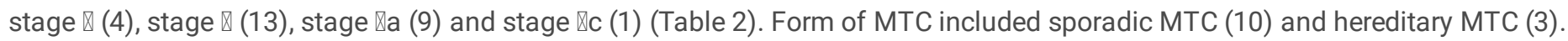

\section{Serum CT in patients with thyroid nodules}

It was clearly seen that concentrations of serum CT in MTC was significantly higher compared with the other subjects. Significantly increased was observed in papillary thyroid carcinoma compared with the healthy groups (Table 3, Figure 1). Statistical significant differences were shown between different stages: MTC stage $\nabla+\square$ and no-MTC stage $\nabla+\square$, MTC stage $\nabla+\square$ and no-MTC stage $\varangle+\square$, MTC stage $\varangle+\square$ and no-MTC stage $\varangle+\square$, MTC stage $\varangle+\square$ and no-MTC stage $\varangle+\rrbracket$, with a $p$-value of $<0.001,<0.001,<0.001$ and $<0.001$, respectively (Figure 2). In the healthy subjects, the 95th percentile of the serum CT levels was $13.8 \mathrm{pg} / \mathrm{mL}$, which was used as a cutoff point for CT positive samples. The abnormal CT levels were noted for $100.0 \%$ in medullary thyroid carcinoma (Table 3 ). Statistical significant differences were shown in serum CT between Medullary thyroid carcinoma and healthy groups.

The concentrations of FNA-CT in nodular goiter, chronic thyroiditis, follicular adenoma, papillary carcinoma, follicular thyroid carcinoma and medullary thyroid carcinoma were $2.0(5.8) \mathrm{pg} / \mathrm{mL}, 2.1 \mathrm{pg} / \mathrm{mL}, 2.2(6.2) \mathrm{pg} / \mathrm{mL}, 2.0$ (5.5) pg/mL, 4.8 (6.6) pg/mL and 
$5000.0(1660.2) \mathrm{pg} / \mathrm{mL}$, respectively. Significantly higher concentrations were found in medullary carcinoma compared with the other subjects (Figure 3 ).

\section{FNA-CT/Serum-CT ratio in thyroid nodules}

The ratio of FNA-CT/Serum-CT in nodular goiter, chronic thyroiditis, follicular adenoma, papillary carcinoma, follicular thyroid carcinoma and medullary thyroid carcinoma were 1.00 (0.93), 0.61, 0.64 (1.01), 0.69 (0.87), 0.96 (1.37) and 4.44 (19.68), respectively. Significantly higher ratio were found in medullary carcinoma compared with the other subjects (Figure 4 ).

\section{CT in different form of MTC}

There were ten cases of sporadic MTC and three cases of hereditary MTC. Statistical significant differences weren't shown in CT concentration between sporadic MTC and hereditary MTC (Figure 5).

\section{Clinical Diagnosis of CT}

In a receiver operating characteristic (ROC) analysis of the MTC, the area under the curve (AUC) of serum CT, FNA-CT and FNACT/serum CT ratio were 1.000, 0.998 and 0.887 respectively (Table 4, Figure 6). The cutoff value of serum CT was $13.8 \mathrm{pg} / \mathrm{mL}$, leading to a sensitivity of $100.00 \%$ and a specificity of $97.99 \%$. The cutoff value of FNA-CT was $91.6 \mathrm{pg} / \mathrm{mL}$, leading to $100.00 \%$ sensitivity and $97.25 \%$ specificity. The cutoff value of FNA-CT/serum CT ratio was 0.99 , leading to $100.00 \%$ sensitivity and $51.83 \%$ respectively (Table 5 , Figure 6). The Kappa values of serum CT, FNA-CT, FNA-CT/serum CT ratio and FNAC were $0.86,0.84,0.14$ and 0.90 , respectively (Table 5).

Serum CT were determined to be false-positive in four patients. FNA-CT were determined to be false-positive in six patients. There was no overlap in the patients who had false positive results with the use of the two methods (Table 6).

\section{Discussion}

CT is a polypeptide hormone consisting of 32 amino acids with a disulfide bridge between position one and seven that is mainly produced by the C-cells of thyroid gland. The measurement of CT concentrations in blood reflects C-cell activity and is performed in general by immunoassay methods. There is many evidences that the measurement of serum CT concentrations in patients with thyroid nodules can lead to an earlier diagnosis of MTC or C-cell hyperplasia $(\mathrm{CCH})$ than the exclusive use of imaging procedures and/or FNA $[4,14]$. In our study, the concentrations of the serum CT in MTC were significantly higher than the other subjects. Statistical significant differences weren't shown in CT concentration between sporadic MTC and hereditary MTC, MTC stage $\nabla+\square$ and MTC stage $\nabla+\rrbracket$. It is necessary to sutdy a larger size of samples to verify the result. The cutoff value of serum CT was $13.8 \mathrm{pg} / \mathrm{mL}$, leading to $100.00 \%$ sensitivity and $97.99 \%$ specificity. The Kappa value was 0.86 , a perfect tumor marker in MTC.

FNA-Ct is used as an ancillary method to accurately diagnose MTC. The diagnosis of MTC is most commonly obtained from the result of Fine-needle aspiration cytology (FNAC) of a new thyroid nodule. But the diagnostic accuracy of this method for MTC is not as high as PTC [15]. The diagnostic accuracy provided by FNAC for MTCs ranges from 50.0 to $82.4 \%[16,15]$. Measurements of FNA-CT, an additional procedures, are required in combination with FNA cytology to diagnose MTC, to avoid false negative results. In our study, significantly higher concentrations were found in medullary carcinoma compared with the other subjects. Furthermore, FNA-CT median concentration was over 100-fold higher compared with no-MTC.

It indicated that serum CT increases in patients with MTC due to the production by MTC cells, which corroborates that FNA-CT is an perfect ancillary method. This is the first study to determine the cutoff value of FNA-CT with CLIA. The ROC curve analysis for MTC nodules and non-MTC nodules revealed that the optimal cutoff value of FNA-CT was $91.60 \mathrm{pg} / \mathrm{mL}$, leading to $100.00 \%$ sensitivity, $97.25 \%$ specificity and 0.84 Kappa value in this research. The cutoff value of FNA-CT was higher than other report [17]. The probable cause of the difference may be the following. First, the study population was consecutive patients with thyroid nodules in this research. Second, differences in methodology might influence measurement consistency. Third, the volume of FNA washout fluid was not standardization. 
To identify relationship between serum CT and FNA-CT, FNA-CT/serum CT ratio in thyroid nodules was investigated. The cutoff value of FNA-CT/serum CT ratio was 0.99 , leading to $51.83 \%$ sensitivity, $13.93 \%$ specificity and 0.14 Kappa value. This result contradicts the concept that CT is produced by C-cell. The probable cause may be the following. First, a total of 189 measurements lower than $2.0 \mathrm{pg} / \mathrm{mL}(<2.0 \mathrm{pg} / \mathrm{mL}$ ) were recorded as $2 \mathrm{pg} / \mathrm{mL}$, which may cause poor results of FNA-CT/serum CT ratio. Second, due to the unstandardized operation of FNA washout fluid, the results couldn't reflect the true state of CT concentration in thyroid nodules.

This is an intriguing finding: It showed that the serum CT were determined to be false-positive in four patients and FNA-CT were determined to be false-positive in six patients. The cause was due to the influence of analytical, physiological, pharmacological, and pathological factors. Notably, there was no overlap in the patients who had false positive results with the use of the two methods. It indicated that FNA-CT could be served as an ancillary perfect method rather than a screening methods for the differential diagnosis between MTC and non-MTC thyroid nodules. When Serum CT suspected of being false positive in detecting MTC, FNA-CT must be performed, which will rule out no-MTC in all of the cases. It corroborated the view of Liu Y [18] that CT should be measured in both the FNA washout fluid and serum when features of MTC are presented or cytology result is inconclusive.

There are some limitations in this study. Because of the low prevalence of MTC, the number of patients involved was small in the study span more than two years. A secondary limitation, this study does not involve the normalization recovery after surgery or response to therapy subsequently.

\section{Conclusions}

Calcitonin in fine-needle aspirate washout fluid and serum were perfect a marker for the differential diagnosis of medullary thyroid carcinoma in patients with thyroid nodules. The optimal cutoff values with CLIA were $13.80 \mathrm{pg} / \mathrm{mL}, 91.60 \mathrm{pg} / \mathrm{mL}$, respectively.

\section{Declarations}

\section{Acknowledgements}

This study was supported by the Natural Science Foundation of Fujian Province (grant no. 2016J01647), the Innovation Profect of Fujian Province Health Department (grant no. 2012-CXB-33) and the youth research project of health and family planning commission of Fujian Province (grant no. 2019-2-51).

Compliance with ethical standards This study was approved by the Institutional Ethics Committee of Zhongshan Hospital, Medical College of Xiamen University and was in compliance with national legislation and the Declaration of Helsinki guidelines. All participants provided written informed consent.

Conflict of interest The authors declare that they have no conflict of interest.

Ethical approval This study was approved by the Institutional Ethics Committee of Zhongshan Hospital, Medical College of Xiamen University and was in compliance with national legislation and the Declaration of Helsinki guidelines. All participants provided written informed consent.

Informed consent Informed consent was obtained from all individual participants included in the study.

\section{References}

1. Wells, S.A., Jr., Asa, S.L., Dralle, H., Elisei, R., Evans, D.B., Gagel, R.F., Lee, N., Machens, A., Moley, J.F., Pacini, F., Raue, F., Frank-Raue, K., Robinson, B., Rosenthal, M.S., Santoro, M., Schlumberger, M., Shah, M., Waguespack, S.G.: Revised American Thyroid Association guidelines for the management of medullary thyroid carcinoma. Thyroid : official journal of the American Thyroid Association 25(6), 567-610 (2015). doi:10.1089/thy.2014.0335

2. Gharib, H., Papini, E., Garber, J.R., Duick, D.S., Harrell, R.M., Hegedus, L., Paschke, R., Valcavi, R., Vitti, P.: AMERICAN ASSOCIATION OF CLINICAL ENDOCRINOLOGISTS, AMERICAN COLLEGE OF ENDOCRINOLOGY, AND ASSOCIAZIONE MEDICI ENDOCRINOLOGI MEDICAL GUIDELINES FOR CLINICAL PRACTICE FOR THE DIAGNOSIS AND MANAGEMENT OF THYROID NODULES-2016 UPDATE. Endocrine practice : official journal of the American College of Endocrinology and the American Association of Clinical Endocrinologists 22(5), 622-639 (2016). doi:10.4158/ep161208.gl 
3. Trimboli, P., Giovanella, L., Crescenzi, A., Romanelli, F., Valabrega, S., Spriano, G., Cremonini, N., Guglielmi, R., Papini, E.: Medullary thyroid cancer diagnosis: an appraisal. Head \& neck 36(8), 1216-1223 (2014). doi:10.1002/hed.23449

4. Bae, Y.J., Schaab, M., Kratzsch, J.: Calcitonin as Biomarker for the Medullary Thyroid Carcinoma. Recent results in cancer research. Fortschritte der Krebsforschung. Progres dans les recherches sur le cancer 204, 117-137 (2015). doi:10.1007/978-3-319-22542-5_5

5. Viola, D., Elisei, R.: Management of Medullary Thyroid Cancer. Endocrinology and metabolism clinics of North America 48(1), 285301 (2019). doi:10.1016/j.ecl.2018.11.006

6. Niederle, M.B., Scheuba, C., Gessl, A., Li, S., Koperek, O., Bieglmayer, C., Riss, P., Selberherr, A., Niederle, B.: Calcium-stimulated calcitonin - The "new standard" in the diagnosis of thyroid C-cell disease - clinically relevant gender-specific cut-off levels for an "old test". Biochemia medica 28(3), 030710 (2018). doi:10.11613/BM.2018.030710

7. Rosario, P.W., Calsolari, M.R.: Basal Serum Calcitonin, After Calcium Stimulation, and in the Needle Washout of Patients with Thyroid Nodules and Mild or Moderate Basal Hypercalcitoninemia. Hormone and metabolic research = Hormon- und Stoffwechselforschung = Hormones et metabolisme 49(2), 129-134 (2017). doi:10.1055/s-0042-121895

8. Rosario, P.W., Calsolari, M.R.: Usefulness of Serum Calcitonin in Patients Without a Suspicious History of Medullary Thyroid Carcinoma and with Thyroid Nodules Without an Indication for Fine-Needle Aspiration or with Benign Cytology. Hormone and metabolic research = Hormon- und Stoffwechselforschung = Hormones et metabolisme 48(6), 372-276 (2016). doi:10.1055/s0042-107246

9. Trimboli, P., Giovanella, L.: Serum calcitonin negative medullary thyroid carcinoma: a systematic review of the literature. Clinical chemistry and laboratory medicine 53(10), 1507-1514 (2015). doi:10.1515/cclm-2015-0058

10. Hassan, A., Siddique, M., Riaz, S., Khan, A.I., Nawaz, M.K., Bashir, H.: Medullary Thyroid Carcinoma: Prognostic Variables And Tumour Markers Affecting Survival. Journal of Ayub Medical College, Abbottabad : JAMC 30(Suppl 1)(4), S627-S632 (2018).

11. Sabia, R., Wagner, M., Susa, K., Lemke, J., Rothermund, L., Henne-Bruns, D., Hillenbrand, A.: Calcitonin concentrations in patients with chronic kidney disease on hemodialysis in reference to parathyroidectomy. BMC research notes 12(1), 439 (2019). doi:10.1186/s13104-019-4479-6

12. Lupoli, G.A., Barba, L., Liotti, A., La Civita, E., Lupoli, R., Riccio, E., Portella, G., Formisano, P., Beguinot, F., Terracciano, D.: Falsely elevated thyroglobulin and calcitonin due to rheumatoid factor in non-relapsing thyroid carcinoma: A case report. Medicine $\mathbf{9 8}(5)$, e14178 (2019). doi:10.1097/MD.0000000000014178

13. Landis, J.R., Koch, G.G.: The measurement of observer agreement for categorical data. biometrics, 159-174 (1977).

14. Trimboli, P., Crescenzi, A., Saggiorato, E., Treglia, G., Giovanella, L.: Novel acquisitions in the diagnosis of medullary thyroid carcinoma. Minerva endocrinologica 42(3), 238-247 (2017). doi:10.23736/s0391-1977.16.02579-7

15. Essig, G.F., Jr., Porter, K., Schneider, D., Debora, A., Lindsey, S.C., Busonero, G., Fineberg, D., Fruci, B., Boelaert, K., Smit, J.W., Meijer, J.A., Duntas, L., Sharma, N., Costante, G., Filetti, S., Sippel, R.S., Biondi, B., Topliss, D.J., Pacini, F., Maciel, R.M., Walz, P.C., Kloos, R.T.: Fine needle aspiration and medullary thyroid carcinoma: the risk of inadequate preoperative evaluation and initial surgery when relying upon FNAB cytology alone. Endocrine practice : official journal of the American College of Endocrinology and the American Association of Clinical Endocrinologists 19(6), 920-927 (2013). doi:10.4158/EP13143.0R

16. Kaushal, S., Iyer, V.K., Mathur, S.R., Ray, R.: Fine needle aspiration cytology of medullary carcinoma of the thyroid with a focus on rare variants: a review of 78 cases. Cytopathology : official journal of the British Society for Clinical Cytology 22(2), 95-105 (2011). doi:10.1111/j.1365-2303.2010.00747.x

17. Kihara, M., Hirokawa, M., Kudo, T., Hayashi, T., Yamamoto, M., Masuoka, H., Higashiyama, T., Fukushima, M., Ito, Y., Miya, A., Miyauchi, A.: Calcitonin measurement in fine-needle aspirate washout fluid by electrochemiluminescence immunoassay for thyroid tumors. Thyroid research 11, 15 (2018). doi:10.1186/s13044-018-0059-4

18. Liu, Y., Yuan, L., Yang, D., Jin, Y.: Serum calcitonin negative mixed medullary-follicular carcinoma initially diagnosed as medullary thyroid carcinoma by fine-needle aspiration cytology: A case report and review of the literatures. Diagnostic cytopathology 46(8), 690-693 (2018). doi:10.1002/dc.23924

\section{Tables}

\section{Table 1}

Clinical characteristics of patients and thyroid nodules

Page 6/15 


\begin{tabular}{|lllllll|}
\hline \multicolumn{7}{|c|}{ Histological Type } \\
& $\begin{array}{l}\text { Nodular } \\
\text { goiter }\end{array}$ & $\begin{array}{l}\text { Chronic } \\
\text { thyroiditis }\end{array}$ & $\begin{array}{l}\text { Follicular } \\
\text { adenoma }\end{array}$ & $\begin{array}{l}\text { Papillary } \\
\text { carcinoma }\end{array}$ & $\begin{array}{l}\text { Follicular } \\
\text { carcinoma }\end{array}$ & $\begin{array}{l}\text { medullary } \\
\text { carcinoma }\end{array}$ \\
\hline $\begin{array}{l}\text { No. of thyroid } \\
\text { nodules (\%) }\end{array}$ & $62(26.4 \%)$ & $3(1.3 \%)$ & $14(6.0 \%)$ & $135(57.4 \%)$ & $4(1.7 \%)$ & $17(7.2 \%)$ \\
\hline Clinical characteristics of patients & & & & & $13(6.1 \%)$ \\
\hline N. Of patients (\%) & $55(25.9 \%)$ & $2(0.9 \%)$ & $11(5.2 \%)$ & $127(59.9 \%)$ & $4(1.9 \%)$ & $9(69.2 \%)$ \\
\hline Female gender(\%) & $35(63.6 \%)$ & $2(100.0 \%)$ & $11(100.0 \%)$ & $101(79.5 \%)$ & $4(100.0 \%)$ & $44.0(33.0)$ \\
\hline Age M(IQR) (years) & $49.0(19.0)$ & 24.5 & $48.0(12.0)$ & $43.0(20.0)$ & $36.5(22.0)$ & \\
\hline
\end{tabular}

Abbreviations: IQR, the interquartile range.

\section{Table 2}

Table 2 Clinical stage of thyroid carcinoma

\begin{tabular}{|c|c|c|c|c|}
\hline $\begin{array}{l}\text { Clinical } \\
\text { stage }\end{array}$ & $\begin{array}{l}\text { Total } \\
\mathbf{n}\end{array}$ & $\begin{array}{l}\text { Papillary thyroid carcinoma } \\
\mathrm{N}(\%)\end{array}$ & $\begin{array}{l}\text { Follicular thyroid carcinoma } \\
\mathrm{N}(\%)\end{array}$ & $\begin{array}{l}\text { medullary thyroid carcinoma } \\
\mathrm{n}(\%)\end{array}$ \\
\hline 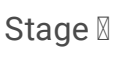 & 117 & $106(90.6 \%)$ & $4(3.4 \%)$ & 7 (6.0\%) \\
\hline 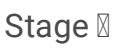 & 4 & $1(25.0 \%)$ & I & $3(75.0 \%)$ \\
\hline 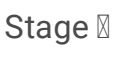 & 13 & $13(100.0 \%)$ & I & I \\
\hline Stage 『a & 9 & 7 (77.8\%) & I & $2(22.2 \%)$ \\
\hline Stage $\varangle \mathrm{b}$ & / & / & I & I \\
\hline 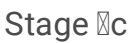 & 1 & / & / & 1 (100.0\%) \\
\hline
\end{tabular}

\section{Table 3}

Serum CT in patients with thyroid nodules 


\begin{tabular}{|c|c|c|c|c|}
\hline & N. Of patients & $\%$ of patients with $\mathrm{CT}>13.8 \mathrm{pg} / \mathrm{mL}$ & Median (IQR) (pg/mL) & $P$ \\
\hline Healthy & 1941 & $97(5.0 \%)$ & $4.0(4.4)$ & \\
\hline \multicolumn{5}{|l|}{ Benign } \\
\hline Nodular goiter & 55 & $0(0.0 \%)$ & $5.4(4.1)$ & 0.862 \\
\hline Chronic thyroiditis & 2 & $0(0.0 \%)$ & 5.5 & 0.457 \\
\hline Follicular thyroid adenoma & 11 & $0(0.0 \%)$ & $7.3(4.0)$ & 0.103 \\
\hline \multicolumn{5}{|l|}{ Malignant } \\
\hline Papillary thyroid carcinoma & 127 & $4(3.2 \%)$ & $5.7(3.9)$ & 0.040 \\
\hline Follicular thyroid carcinoma & 4 & $0(0.0 \%)$ & $3.6(2.7)$ & 0.924 \\
\hline Medullary thyroid carcinoma & 13 & $13(100.0 \%)$ & $301.0(1290.0)$ & $<0.001$ \\
\hline
\end{tabular}

Abbreviations: IQR, the interquartile range.

Table 4

The area under the curve of serum CT, FNA-CT and FNA-CT/Serum CT ratio

\begin{tabular}{|lll|}
\hline Test Result Variable & Area & $95 \% \mathrm{Cl}$ \\
\hline Serum CT & 1.000 & $0.999-1.000$ \\
\hline FNA-CT & 0.998 & $0.993-1.000$ \\
\hline FNA-CT/Serum CT ratio & 0.887 & $0.820-0.955$ \\
\hline
\end{tabular}

Statistical significant differences weren't shown in area under the curve between all varialbe.

Table 5

Clinical diagnosis of medullary thyroid carcinoma in patients with thyroid nodules 


\begin{tabular}{|c|c|c|c|c|c|c|c|c|c|}
\hline & \multirow{2}{*}{\multicolumn{2}{|c|}{$\begin{array}{l}\text { Histological } \\
\text { diagnosis (gold } \\
\text { standard) }\end{array}$}} & \multirow{3}{*}{$\begin{array}{l}\text { Sensitivity(\%) } \\
(95 \% \mathrm{Cl})\end{array}$} & \multirow{3}{*}{$\begin{array}{l}\text { Specificity(\%) } \\
(95 \% \mathrm{Cl})\end{array}$} & \multirow{3}{*}{$\begin{array}{l}\text { PPV(\%) } \\
(95 \% \\
\text { Cl) }\end{array}$} & \multirow{3}{*}{$\begin{array}{l}\text { NPV(\%) } \\
(95 \% \\
\text { Cl) }\end{array}$} & \multirow{3}{*}{$\begin{array}{l}\text { PLR } \\
(95 \% \\
\text { Cl) }\end{array}$} & \multirow{3}{*}{$\begin{array}{l}\text { NLR } \\
(95 \% \\
\text { Cl) }\end{array}$} & \multirow[t]{3}{*}{ Kappa Value(Sig) } \\
\hline & & & & & & & & & \\
\hline & Positive & Negative & & & & & & & \\
\hline \multicolumn{10}{|c|}{ Serum CT (cutoff value was $13.8 \mathrm{pg} / \mathrm{mL}$ ) } \\
\hline Positive & 13 & 4 & 100.00 & 97.99 & 76.47 & 100.00 & 49.75 & 0.00 & 0.86 \\
\hline Negative & 0 & 195 & $\begin{array}{l}(71.66- \\
100.00)\end{array}$ & $(94.60-99.35)$ & $\begin{array}{l}(49.76- \\
92.18)\end{array}$ & $\begin{array}{l}(97.59- \\
100.00)\end{array}$ & $\begin{array}{l}(18.86- \\
131.25)\end{array}$ & $\begin{array}{l}\mathrm{NaN}- \\
\text { Infinity }\end{array}$ & $(0.00)$ \\
\hline \multicolumn{10}{|c|}{ FNA-CT (cutoff value was $91.6 \mathrm{pg} / \mathrm{mL}$ ) } \\
\hline Positive & 17 & 6 & 100.00 & 97.25 & 73.91 & 100.00 & 36.33 & 0.00 & 0.84 \\
\hline Negative & 0 & 212 & $\begin{array}{l}(77.08- \\
100.00)\end{array}$ & $(93.82-98.88)$ & $\begin{array}{l}(51.31- \\
88.92)\end{array}$ & $\begin{array}{l}(97.78- \\
100.00)\end{array}$ & $\begin{array}{l}(16.05- \\
79.98)\end{array}$ & $\begin{array}{l}\mathrm{NaN}- \\
\text { Infinity }\end{array}$ & $(0.00)$ \\
\hline \multicolumn{10}{|c|}{ FNA-CT / serum CT ratio (cutoff value was 0.955 ) } \\
\hline Positive & 17 & 105 & 100.00 & 51.83 & 13.93 & 100.00 & 2.08 & 0.00 & 0.14 \\
\hline Negative & 0 & 113 & $\begin{array}{l}(77.07- \\
100.00)\end{array}$ & $(45.00-58.60)$ & $\begin{array}{l}(8.56- \\
21.65)\end{array}$ & $\begin{array}{l}(95.90- \\
100.00)\end{array}$ & $\begin{array}{l}(1.81- \\
2.38)\end{array}$ & $\begin{array}{l}\text { NaN- } \\
\text { Infinity }\end{array}$ & $(0.00)$ \\
\hline \multicolumn{10}{|l|}{ FNAC } \\
\hline Positive & 14 & 0 & 82.35 & 100 & 100 & 98.64 & Infinity & 0.18 & 0.90 \\
\hline Negative & 3 & 218 & (55.80-95.33) & $\begin{array}{l}(97.84- \\
100.00)\end{array}$ & $\begin{array}{l}(73.24- \\
100.00)\end{array}$ & $\begin{array}{l}(95.76- \\
99.65)\end{array}$ & $\begin{array}{l}\mathrm{NaN}- \\
\text { Infinity }\end{array}$ & $\begin{array}{l}(0.06- \\
0.49))\end{array}$ & $(0.00)$ \\
\hline
\end{tabular}

Abbreviations: PPV, positive predictive value; NPV, negative predictive value; PLR, positive likelihood ratio; NLR, negative likelihood ratio; $\mathrm{NaN}$, means that the calculation cannot be performed because the values entered include one or more instances of zero.

Table 6

False-positive of Serum CT or FNA-CT 


\begin{tabular}{|llll|}
\hline No. & Histological Type & Serum CT (cutoff value was $13.8 \mathrm{pg} / \mathrm{mL}$ ) & FNA-CT (cutoff value was 91.6 pg/mL) \\
\hline 1 & Papillary carcinoma & $17.4(+)$ & $9.8(-)$ \\
\hline 2 & Papillary carcinoma & $17.4(+)$ & $7.1(-)$ \\
\hline 3 & Papillary carcinoma & $18.2(+)$ & $6.8(-)$ \\
\hline 4 & Papillary carcinoma & $41.3(+)$ & $2.0(-)$ \\
\hline 5 & Papillary carcinoma & $5.7(-)$ & $108.7(+)$ \\
\hline 6 & Papillary carcinoma & $7.2(-)$ & $110.6(+)$ \\
\hline 7 & Papillary carcinoma & $8.4(-)$ & $161.7(+)$ \\
\hline 8 & Papillary carcinoma & $5.2(-)$ & $185.8(+)$ \\
\hline 9 & Nodular goiter & $2.3(-)$ & $251.4(+)$ \\
\hline 10 & Papillary carcinoma & $7.1(-)$ & $2558.9(+)$ \\
\hline
\end{tabular}

\section{Figures}

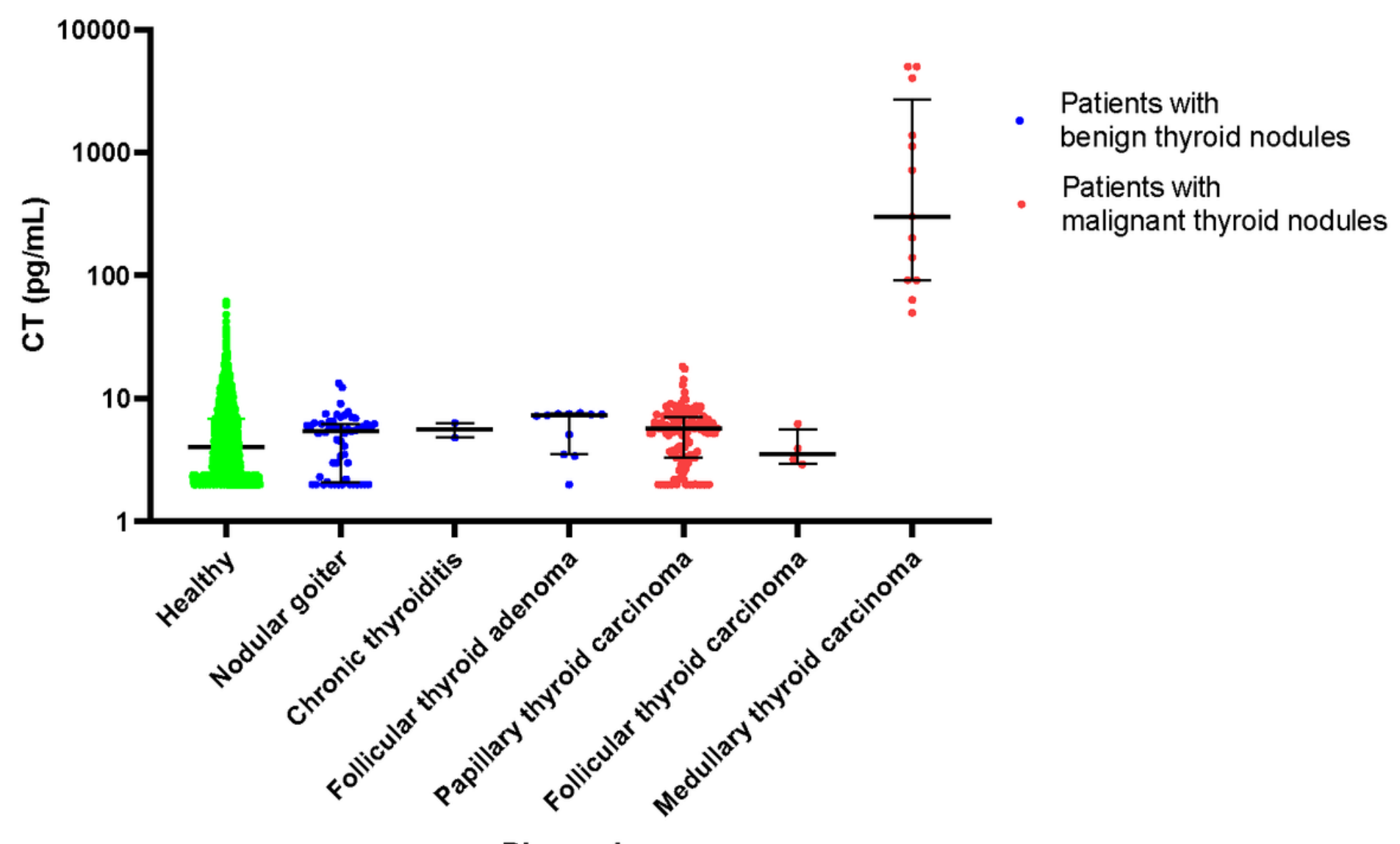

Figure 1

Scatter plot of serum CT The following groups in CT concentration were shown statistical significant differences between each other: medullary thyroid carcinoma and healthy subject, medullary thyroid carcinoma and nodular goiter, medullary thyroid carcinoma and chronic thyroiditis, medullary thyroid carcinoma and follicular thyroid adenoma, medullary thyroid carcinoma and papillary thyroid carcinoma, medullary thyroid carcinoma and follicular thyroid carcinoma, papillary thyroid carcinoma and healthy subject, with a pvalue of $<0.001,<0.001,<0.001,<0.001,<0.001,<0.001$ and 0.004 , respectively. 


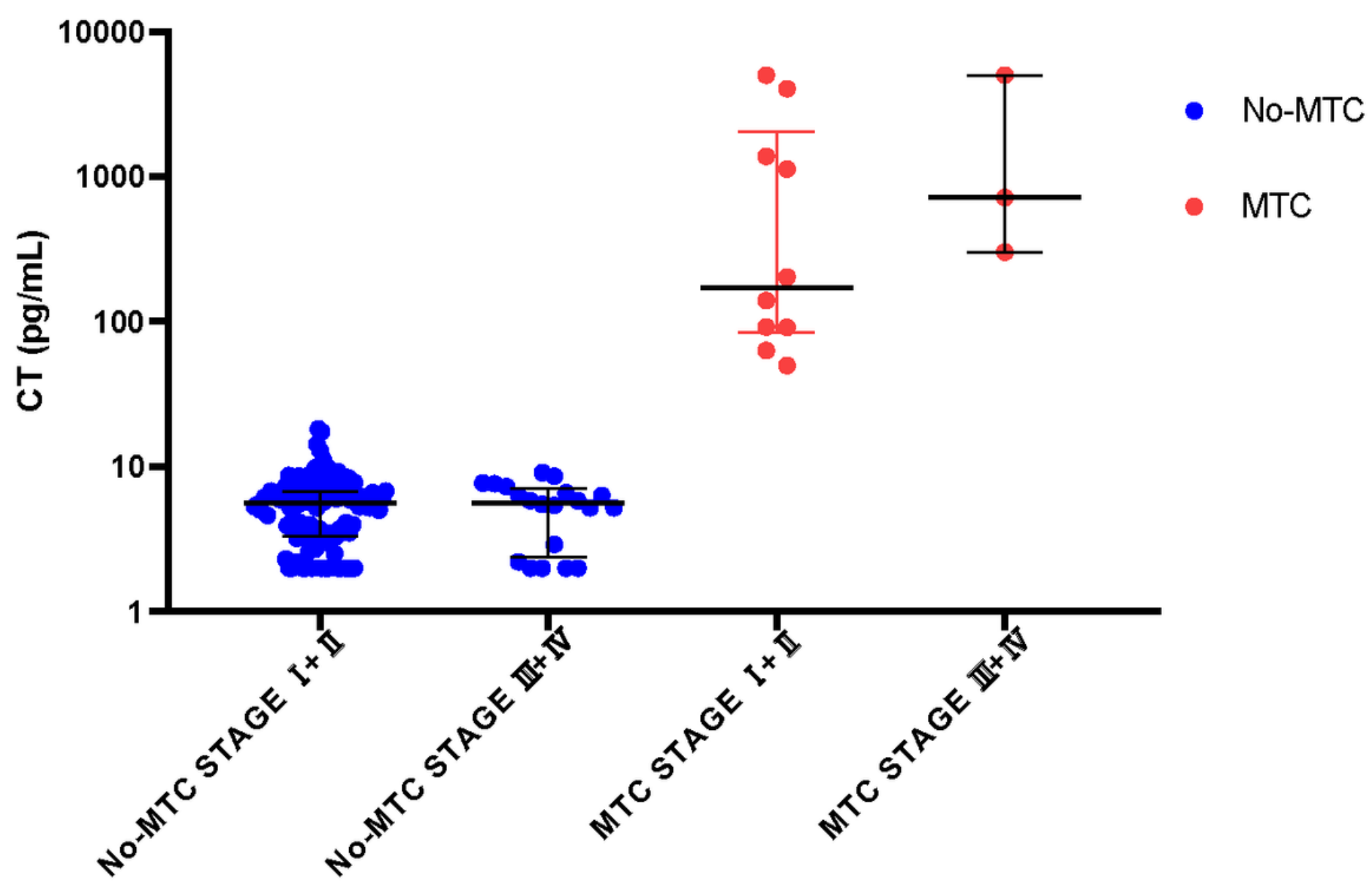

Clinical Stage

Figure 2

Scatter plot of CT in thyroid carcinoma Abbreviations: MTC, medullary thyroid cancer; non-MTC, non medullary thyroid cancer. The following groups in CT were shown statistical significant differences between each other: MTC stage $\varangle+\rrbracket$ and no-MTC stage $\nabla+\rrbracket, M T C$

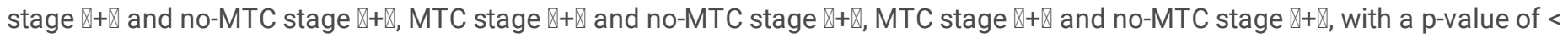
$0.001,<0.001,<0.001$ and $<0.001$, respectively. 


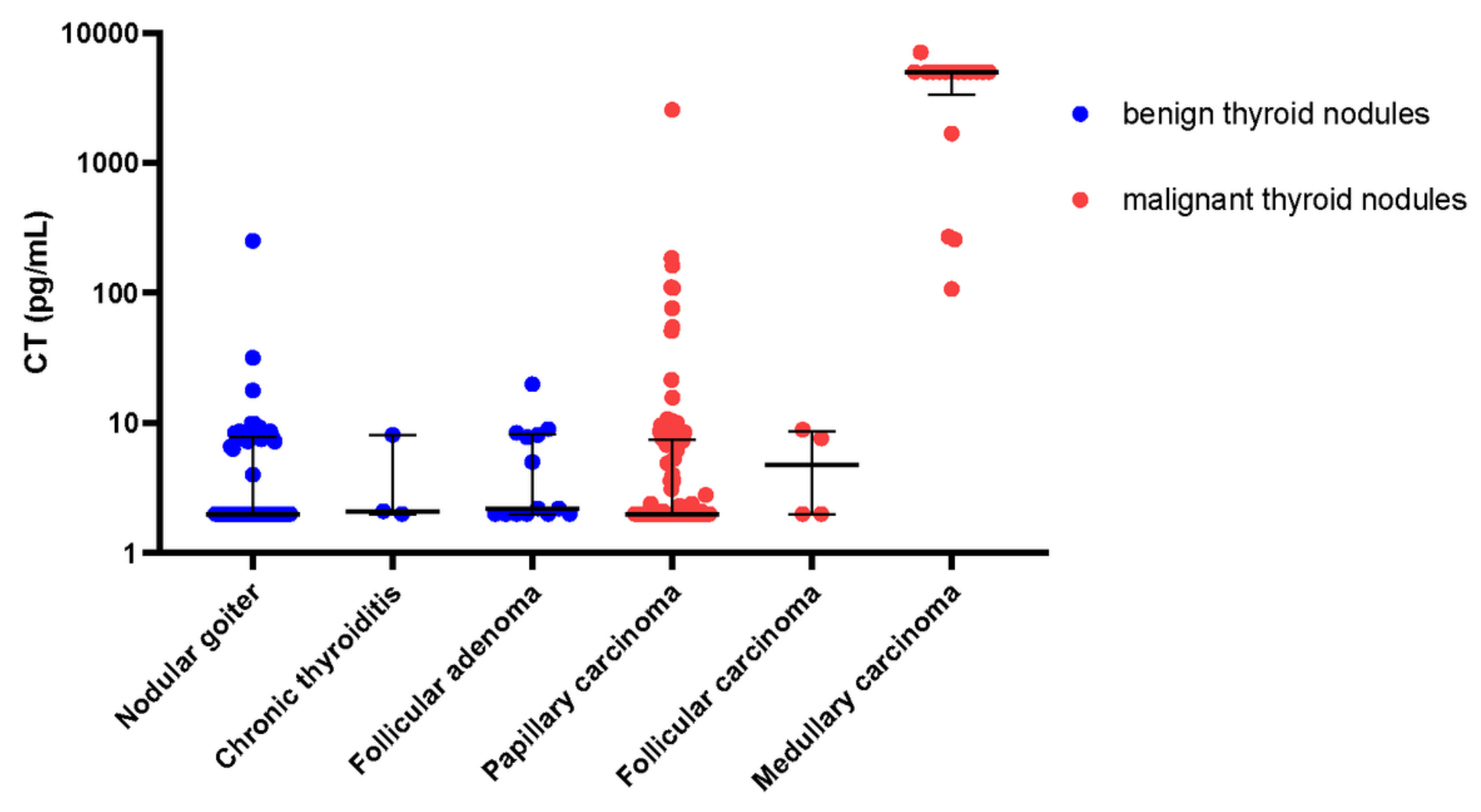

Histological type

Figure 3

Scatter plot of FNA-CT in thyroid nodules The following groups in CT concentration were shown statistical significant differences between each other: medullary carcinoma and nodular goiter, medullary carcinoma and chronic thyroiditis, medullary carcinoma and follicular adenoma, medullary carcinoma and papillary carcinoma, medullary carcinoma and follicular carcinoma, with a p-value of < $0.001,<0.001,<0.001,<0.001$ and $<0.001$, respectively. 


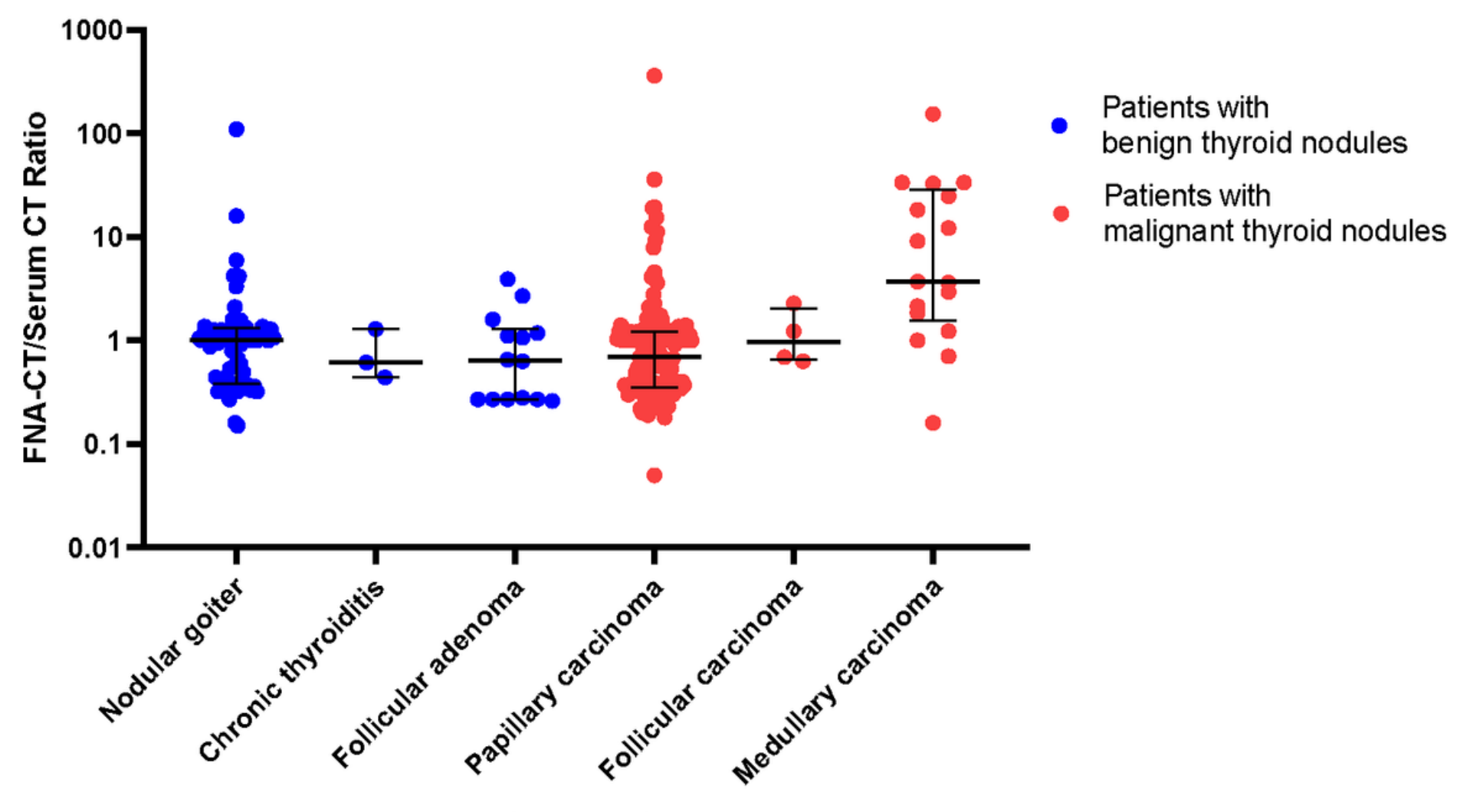

Histological type

Figure 4

Scatter plot of FNA-CT / Serum CT ratio in thyroid nodules Abbreviations: CT, Calcitonin; FNA-CT, Calcitonin in fine-needle aspirate washout fluid. The following groups in CT concentration were shown statistical significant differences between each other: medullary carcinoma and nodular goiter, medullary carcinoma and chronic thyroiditis, medullary carcinoma and follicular adenoma, medullary carcinoma and papillary carcinoma, medullary carcinoma and follicular carcinoma, with a p-value of $<0.001,<0.001,0.033,<0.001$ and $<0.001$, respectively. 


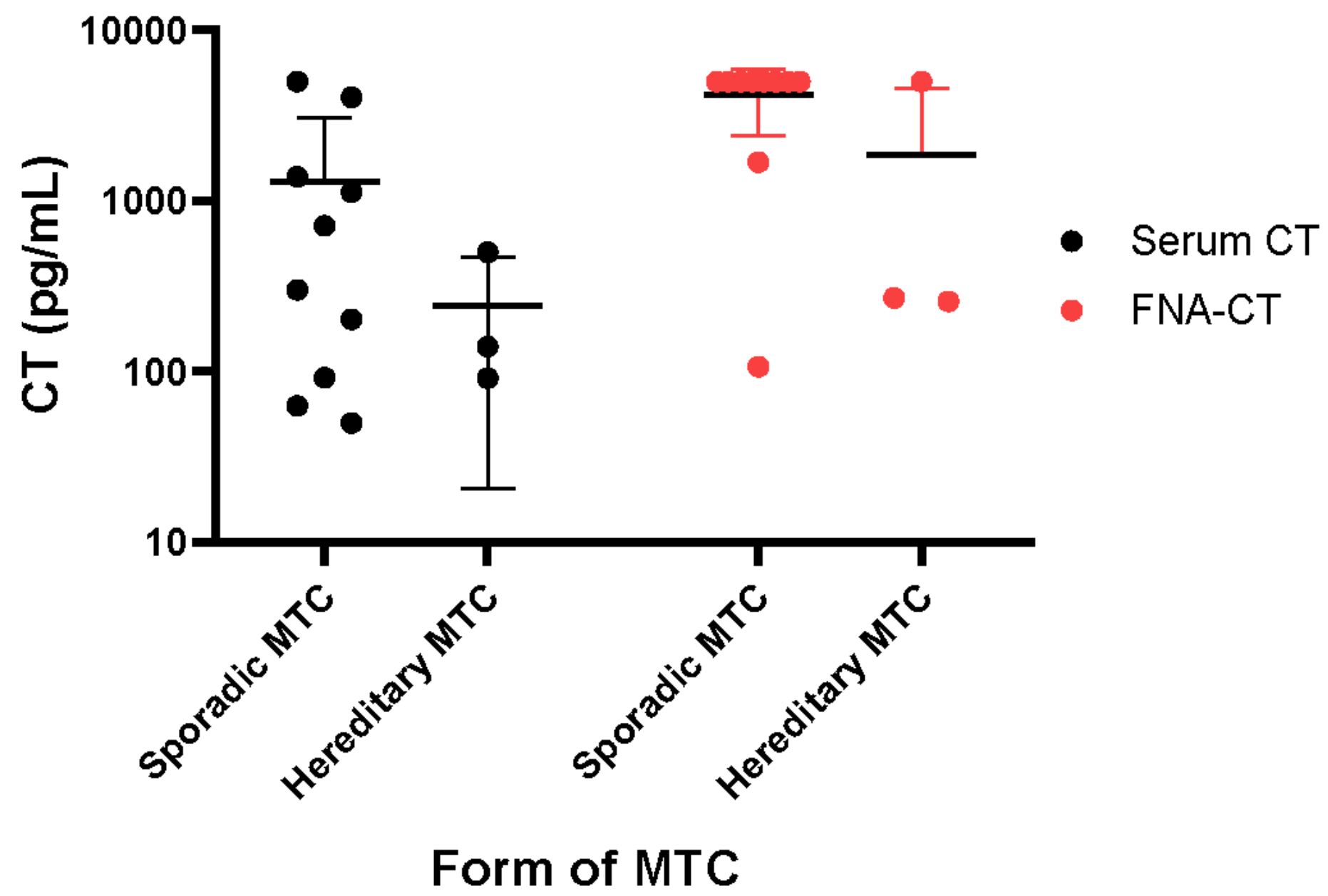

Figure 5

Scatter plot of CT in different form of MTC Abbreviations: MTC, Medullary thyroid cancer; CT, Calcitonin. Statistical significant differences weren't shown in CT concentration between sporadic MTC and hereditary MTC 


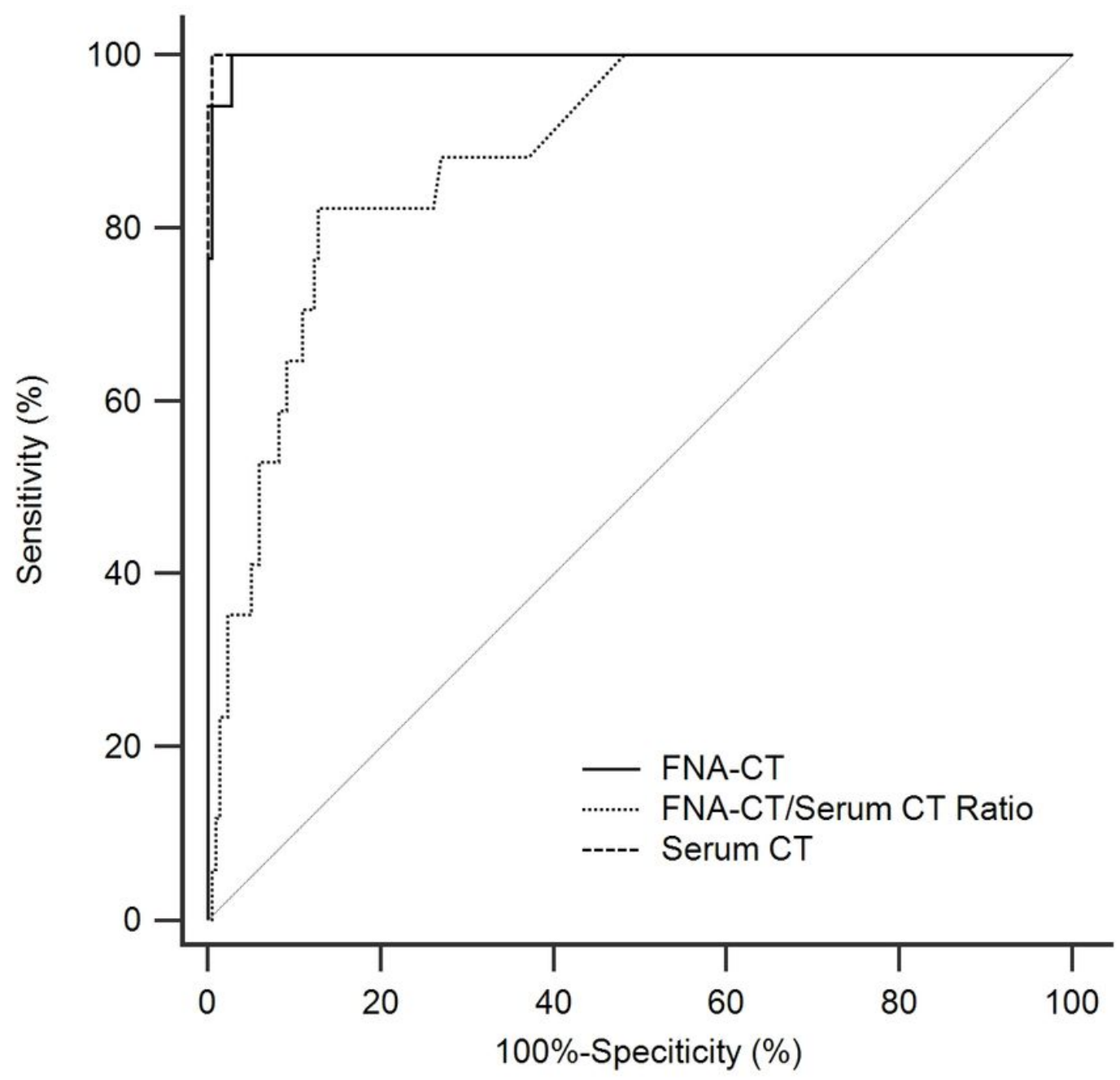

Figure 6

ROC in medullary thyroid carcinoma 